\title{
DIMINUTIVO DO GERÚNDIO: OPÇÕES ASPECTUAIS DA FALA DO GUARAPUAVANO
}

\author{
MÔNICA CRISTINA METZ ${ }^{1}$ \\ (UEM)
}

\begin{abstract}
RESUMO: Ancorado numa concepção interacionista de língua, o objetivo geral deste trabalho é refletir sobre as funções desempenhadas pelo uso específico das formas verbais em gerúndio diminutivo na região de Guarapuava no Paraná. Mais especificamente, discute-se a hipótese de que o uso de perífrases formadas por verbos no gerúndio diminutivo está relacionado a opções aspectuais da ação representada pelo verbo. As discussões fundamentam-se, principalmente, nos estudos com base funcionalista e/ou descritiva de Ilari e Basso (2008), Bagno (2013) e Perini (2010) acerca da questão do aspecto no português brasileiro, como também nos estudos sobre o diminutivo em variedades do português do Brasil de Guimarães e Mendes (2010), Armelin (2011; 2015) e Rocha (2016). Por meio de uma análise interpretativa, discutimos três características dos usos do diminutivo no gerúndio que permitem considerá-los como um recurso linguístico capaz de adicionar nuances de significado por meio de aspecto gramatical ao processo expresso pelo predicado: a) a coocorrência no sistema entre as formas primitivas e as formas diminutivas; $b$ ) a diferença semântica entre as formas diminutiva e primitiva reside numa dimensão aspectual do evento expresso pelo verbo que não se resume em função hipocorística; e c) as opções (primitivo vs. diminutivo) se exprimem por recursos gramaticais da língua, isto é, pelo uso ou não do diminutivo.
\end{abstract}

Palavras-Chave: Aspecto; Gerúndio; Diminutivo.

ABSTRACT: Based on an interactionist conception of language, the aim of this paper was to reflect on the functions employed by the specific use of diminutive gerund verbal forms in the region of Guarapuava in Paraná. More specifically, it was discussed the hypothesis that the use of periphrases formed by diminutive gerund verbs is related to aspectual options of action represented by the verb. The discussions were grounded, mainly, on the studies with functionalist and/or descriptive basis from Ilari and Basso (2008), Bagno (2013) and Perini (2010) about the theme of Brazilian Portuguese aspect, as well as on studies about the diminutive in Brazilian Portuguese variants from Guimarães and Mendes (2010), Armelin (2011; 2015) and Rocha (2016). Through an interpretative analysis, we discussed three characteristics of the diminutive use in gerund which allowed us to considered them a linguistic resource able to subjoin meaning features through grammar aspect to the process expressed by the predicate: a) the co-occurrence in the system between primitive and diminutive forms; $b$ ) the semantic difference between diminutive and primitive forms resides in an aspectual dimension of the event expressed by the verb which comprises more than a hypocortical function; and c) the options (primitive vs. diminutive) are expressed by grammatical resources from the language, that is, by the use or not of diminutive.

Keywords: Aspect; Gerund; Diminutive.

${ }^{1}$ Doutoranda em Letras, linha de pesquisa ensino-aprendizagem de línguas, na Universidade Estadual de Maringá. E-mail: monicametz@gmail.com 


\section{INTRODUZINDINHO}

Gírias, pronúncias e outras particularidades dialetais, não apenas prosódicas, mas também morfológicas, caracterizam a fala de uma determinada região e muitas vezes são até consideradas patrimônio cultural do local. Nesse sentido, referências às peculiaridades das diversas variedades do português brasileiro são facilmente encontradas em meios de divulgação científica e/ou midiática. Na região de Guarapuava no Paraná, isso não é diferente, e o reconhecimento daquilo que é típico do falar guarapuavano salta aos olhos daqueles que advêm de outras regiões.

Introduzindinho este trabalho, por exemplo, vamos marcandinho uma das características mais marcantes da fala guarapuavana: o gerúndio no diminutivo.

Numa abordagem tradicional, os verbos são analisados a partir de suas flexões (tempos, modos, pessoas, vozes), com fins, geralmente, prescritivos e classificatórios. Numa abordagem funcionalista, tal como a perspectiva de Ilari e Basso (2008), propõe-se estudar o verbo a partir das funções que desempenha, as quais, muitas vezes, não estão ligadas apenas às flexões, mas aos significados dos verbos. Estudos funcionalistas têm como característica, desse modo, a adoção de uma concepção de língua enquanto instrumento de comunicação e/ou interação social "que, como tal, não pode ser analisada como um objeto autônomo, mas como uma estrutura maleável, sujeita a pressões oriundas das diferentes situações comunicativas, que ajudam a determinar sua estrutura gramatical" (KENEDY; MARTELOTTA, 2003, p. 20).

Nesse sentido, ancoradas numa concepção interacionista de língua, as propostas de análise no presente estudo são mais semânticas do que propriamente morfológicas e voltam-se para uma discussão interpretativa da função comunicativa do diminutivo em formas gerundivas em determinada variedade do português. Sob essa perspectiva, o objetivo geral deste trabalho é refletir sobre as funções desempenhadas pelo uso específico das formas verbais em gerúndio diminutivo (por exemplo, chovendinho, correndinho, passeandinho, introduzindinho) na região de Guarapuava no Paraná. Mais especificamente, discute-se a hipótese de que o uso de perífrases formadas por verbos no gerúndio diminutivo está relacionado a opções aspectuais da ação representada pelo verbo, e não, simplesmente, a formas hipocorísticas, tal como os usos do diminutivo, em geral, têm sido interpretados em alguns contextos.

As discussões fundamentam-se, principalmente, nos estudos com base funcionalista e/ou descritiva de Ilari e Basso (2008), Bagno (2013) e Perini (2010) acerca da questão do aspecto no português brasileiro, como também nos estudos sobre o diminutivo em variedades do português do Brasil de Teixeira (2008), Armelin (2011; 2015), Rocha (2016) e Guimarães e Mendes (2010).

\section{A QUESTÃO DO DIMINUTIVO}

Para buscar compreender a função do uso do diminutivo em formas de gerúndio, esboçamos brevemente, nesta seção, algumas considerações em relação ao estatuto analítico do diminutivo em alguns trabalhos sobre português brasileiro. 
Teixeira (2008), em estudos sobre diminutivos em variedades do português brasileiro, traça uma síntese das análises de alguns autores acerca dos diminutivos -inho e -zinho nessas variedades. Uma das questões controversas entre os autores, e também presente nas gramáticas normativas, conforme Teixeira (2008), está no tratamento dos diminutivos ou como parte dos processos de flexão ou dos processos de derivação. Nesse sentido, não há consenso em relação à categoria analítica dos diminutivos. O que observamos na síntese da pesquisadora é que as análises apresentadas sobre o diminutivo se dão em relação às classes nominais e a alguns advérbios, mas não há análises do diminutivo em formas verbais (mesmo as participais ou as gerundivas).

Em artigo publicado por Armelin (2011, p. 05), no qual se analisa a relação entre as marcas do diminutivo e do aumentativo no português brasileiro, encontramos uma referência ao uso dessas marcas na forma gerundiva dos verbos, sem, contudo, análise ou reflexão acerca do uso específico do diminutivo nas formas em gerúndio:

os formadores mais produtivos de diminutivo e aumentativo no PB são respectivamente: -inho/-zinho e -ao/-zão. Tais elementos podem se anexar a diferentes categorias, como substantivo, adjetivo, advérbio e forma gerundiva dos verbos, como se pode ver nos exemplos abaixo:

a. Menino - menininho/meninão

b. Bonito - bonitinho/bonitão

c. Lento - lentinho/lentão

d. correndo - correndinho/correndão.

Em sua tese de doutorado, por sua vez, Armelin (2015) discute a relação entre os diminutivos e o gênero nos nominais do português brasileiro. Nesse estudo, a autora traz exemplos de ocorrências do diminutivo em formas gerundivas, inclusive com flexões de gênero, no entanto, suas análises não recobrem essas ocorrências. Nas palavras da pesquisadora,

está fora do escopo desta tese desenvolver um esquema que dê conta da formação de gerúndios ou de particípios do PB. É importante ressaltar, no entanto, que a correlação entre a possibilidade de flexão de gênero/número e a possibilidade de anexação do diminutivo parece estar apontando para uma análise que associe a formação diminutiva à presença de traços nominais (ARMELIN, 2015, pp. 117-118).

A hipótese levantada por Armelin (2015) no que se refere a uma associação do diminutivo a traços nominais presentes nas diferentes classes gramaticais parece configurar um caminho bem produtivo para uma análise mais formalizada acerca das ocorrências do diminutivo em formas gerundivas, uma vez que esses casos, tradicionalmente, foram tidos como excepcionais. Abre-se aqui uma perspectiva para um trabalho futuro que aborde mais formalmente esse fenômeno. Por ora, o que nos interessa, nos estudos de Armelin $(2011 ; 2015)$, é justamente a ideia de o diminutivo -inho ser produtivo no português brasileiro e, portanto, poder ocorrer em formas do gerúndio, e isso é o que observamos com bastante recorrência na fala dos sujeitos da região de Guarapuava no Paraná. 
Também na primeira edição do Curso prático da língua portuguesa e sua literatura de Jânio Quadros (1966, p. 191), encontramos referência ao uso do diminutivo em formas verbais: "as formas diminutivas têm grande emprego na linguagem familiar, onde, por vezes, até os verbos e os advérbios são empregados no diminutivo (cedinho, longinho, agorinha, andandinho, dormindinho) além dos nomes próprios".

Rocha (2016) delineia os critérios apontados por diferentes morfólogos para a consideração dos diminutivos como processos de flexão ou de derivação e, a partir da análise desses critérios, defende que os diminutivos apresentam características pertinentes à sua caracterização enquanto morfemas flexionais. Nas palavras do autor:

Seguindo a linha inaugurada por Câmara Jr (1970), a quase unanimidade das pesquisas linguísticas classifica o grau como derivação em português. Assume-se que os afixos de grau não são motivados por nenhum princípio de ordem gramatical, ressaltando a natureza não-obrigatória de tais morfemas. Sendo assim, a literatura tem defendido a ideia de que a subjetividade do falante deve ser entendida como ponto central tanto no acionamento do grau como em sua atribuição de significado a uma base (ROCHA, 2016, p. 37).

Em contraposição a essa perspectiva, o pesquisador, ancorado nas discussões de Booij (1994, 1996), assume a existência de dois tipos de morfemas flexionais, a saber, aqueles de origem sintática (do tipo contextual), como, por exemplo, os marcadores de concordância número-pessoal, e aqueles de ordem semântica, mas que em certa medida podem ter relevância sintática (do tipo inerente), como, por exemplo, o tempo e o aspecto dos verbos. Assim, "os critérios que identificam a flexão devem levar em conta o fato de que essa morfologia possui dois tipos. Um deles, a 'inerente', é determinado mais semântica que sintaticamente" (ROCHA, 2016, p. 88). O outro tipo se refere à flexão contextual, requerida pela sintaxe. Para Rocha (2016), a flexão, dessa forma, deve ser compreendida como um fenômeno heterogêneo, com o qual coadunam determinadas características derivacionais.

As discussões de Rocha (2016) acerca da consideração dos diminutivos como flexão indicativa de gradação (do tipo inerente) oferecem relevantes contribuições para o presente trabalho no sentido de traçar características dos diminutivos que podem apontar para nossa hipótese de considerar os usos do gerúndio como formas de marcar gramaticalmente opções aspectuais. Conforme o autor,

o grau diminutivo do português brasileiro apresenta as seguintes características: alta produtividade; manutenção da categoria da base; motivação e regularidade semântica; recursividade; e possibilidade de "lexicalização". Sendo assim, diferentemente da postura inaugurada por Câmara Jr (1970), tais morfemas são flexionais (ROCHA, 2016, p. 88).

No que se refere à característica de alta produtividade, o pesquisador aponta a possibilidade de o diminutivo ocorrer em diferentes classes gramaticais, como substantivos (cachorrinho), adjetivos (bonitinho), advérbios (devagarinho), pronomes (euzinho), formas participais e gerundivas de verbos (corridinho, correndinho). Em todas as ocorrências, não há alteração da categoria da base 
da palavra, permanecendo, dessa forma, a classe gramatical da forma primitiva, conforme a segunda característica. Em relação à terceira característica, Rocha (2016) aponta uma motivação semântica e uma regularidade no conteúdo gramatical que o diminutivo atribui a sua base, de modo que "sua contribuição composicional para o significado leva em conta intensificação ou atenuação de uma determinada propriedade/conceito" (ROCHA, 2016, p. 92). No que diz respeito à recursividade e à possibilidade de lexicalização, o pesquisador demonstra que essas características (tradicionalmente atribuídas aos processos de derivação) não impedem a consideração dos diminutivos como morfemas flexionais do tipo inerente. ${ }^{2}$

A análise de Rocha (2016) em considerar os diminutivos, e por consequência os aumentativos, como morfemas flexionais indicativos de gradação requeridos semanticamente, por isso considerados como do tipo de flexão inerente, pode auxiliar-nos na reflexão acerca dos seus usos específicos em formas gerundivas. Conforme as conclusões do pesquisador, "o uso do diminutivo produz efeitos de significado que inviabilizam a mera intercambialidade entre forma primitiva e forma complexa" (ROCHA, 2016, p. 92) e, portanto, deve ser considerado como uma forma flexional. Entretanto, ainda há muito a se discutir em relação aos sentidos provocados pelo diminutivo nas diferentes classes gramaticais, como conclui Rocha (2016), ainda faltam explicar sentidos que vão além do conteúdo de grau.

Nesse sentido, encontramos também nas análises de Guimarães e Mendes (2010) a necessidade de estudos referentes ao conteúdo semântico dos diminutivos nas distintas classes gramaticais, conforme podemos verificar a seguir:

(...) 'inh' também tem a capacidade de se encaixar em unidades monomorfêmicas não-nominais, como advérbios e, em alguns dialetos/idioletos, verbos gerundivos, tal como em (44).

$$
\begin{aligned}
& \text { a: Eu vou tomar banho [agor[inh]a] mesmo } \\
& \text { b: O Gesoel e a Ana estão }[[\text { namor }][\mathrm{a}][\mathrm{nd}[\mathrm{inh}] \mathrm{o}]] \text { no sofá da sala. } \\
& \text { c: Eu vou ali na farmácia }[[\operatorname{corr}][\mathrm{e}][\mathrm{nd}[\mathrm{inh}] \mathrm{o}]] \text {, e já te trago o remédio. }
\end{aligned}
$$

O tratamento semântico desses casos ainda é um mistério. Há diminutivos de tamanho, afetivos, depreciativos, encurtadores de intervalo temporal, etc, e estamos longe de ter um tratamento unificado para tudo isso (GUIMARAES e MENDES, 2010, p. 10). ${ }^{3}$

As discussões de Guimarães e Mendes (2010), como também de Rocha (2016), em relação às possibilidades semânticas dos diminutivos, demonstram que há ainda muito a se discutir a respeito quando se olha para classes gramaticais

\footnotetext{
${ }^{2}$ Extrapola os limites definidos para este trabalho uma discussão mais aprofundada das características dos processos de derivação e de flexão. Limitamo-nos, neste momento, a uma breve exposição das conclusões apresentadas por Rocha (2016), com as quais nossas hipóteses estabelecem certo diálogo. Para aprofundamento dessas características, recomendamos a leitura dos trabalhos de Rocha (2016) e Armelin (2015).

${ }^{3}$ Guimarães e Mendes (2010) defendem o caráter infixal do morfema de diminutivo no português brasileiro, por esse motivo referem-se ao morfema de diminutivo utilizando -inh. Está fora do escopo deste trabalho uma discussão acerca desse caráter infixal, uma vez que os usos do diminutivo em formas gerundivas aqui analisados configuram-se a partir do morfema -inho.
} 
tradicionalmente deixadas fora do escopo analítico dos diminutivos, considerando os seus usos como excepcionais, como é o caso, por exemplo, do diminutivo nas formas gerundivas. Encontramos algumas pistas para a análise desses casos em Guimarães e Mendes (2010):

'inh', por alguma razão, não pode se combinar com particípios nos dialetos em que pode se combinar com gerúndios (e.g. Ele vem bajulandinho a Ana todos os dias versus *Ele tem bajuladinho a Ana todos os dias). Especulamos que isso tenha a ver com aspecto, em última instância, pois o particípio não "abre o intervalo temporal" a ser encurtado ou alongado, por assim dizer (GUIMARÃES e MENDES, 2010, p. 12). ${ }^{4}$

É justamente na direção da especulação dos autores que este trabalho reflete sobre a combinação de gerúndio e diminutivo feita pelos guarapuavanos, ou seja, interpretamos a função do diminutivo no gerúndio em termos aspectuais.

Em pesquisas realizadas na internet sobre o uso do gerúndio no diminutivo (Cf., por exemplo, CARIELLO, 2016 e OLIVEIRA, 2016), encontramos informações de que esse uso é, também, recorrente em algumas cidades do interior do estado de São Paulo, na região de Sorocaba. Essas marcas, assim como em Guarapuava, constituem uma das características marcantes da variedade linguística falada na região. ${ }^{5}$

Nesses termos, analisamos, a partir da discussão sobre o aspecto no português do Brasil, os usos do diminutivo nas formas verbais em gerúndio como um recurso linguístico capaz de adicionar nuances de significado por meio de aspecto gramatical ao processo expresso pelo predicado.

\section{O ASPECTO EM PORTUGUÊS}

O aspecto é descrito pela tradição linguística como uma opção do falante no sentido de representar o estado de coisa expresso pelo verbo segundo uma perspectiva. De acordo com Ilari e Basso (2008, p. 285), na língua portuguesa "as opções aspectuais se exprimem pela aplicação a uma mesma palavra de recursos gramaticais específicos (flexões, construções)"'. Dessa forma, o aspecto não está relacionado com ordenações cronológicas de referência temporal, mas com "um conjunto limitado de opções e de sentidos 'abstratos' proporcionados pela gramática da língua” (ILARI e BASSO, 2008, p. 287). Trata-se, portanto, de buscar compreender a relação entre as formas pelas quais o verbo pode se apresentar com diferentes perspectivas que se pode assumir em relação ao processo representado pelo verbo/predicado.

Nesse sentido, Ilari e Basso (2008, p. 288) descrevem três principais opções, no português do Brasil, que representam perspectivas diferentes sobre um processo a partir de expressões gramaticalizadas na língua, quais sejam:

\footnotetext{
${ }^{4}$ É interessante mencionar que os pesquisadores vinculam-se à Universidade Federal do Paraná, o que nos permite postular que o contato dos autores com variedades linguísticas da região pode ter contribuído para a especulação levantada.

${ }^{5}$ Encontramos também indícios desses usos na região de Cascavel no Paraná. Sinalizamos aqui uma perspectiva para trabalhos futuros que busquem investigar esses usos em outros contextos a fim de explorar mais formalmente a gramaticalidade dessas construções.
} 
(i) Global/parcial (ou perfectivo/imperfectivo; concluso/inconcluso);

(ii) Perfectivo acabado/perfectivo indeterminado;

(iii) Progressivo/não progressivo.

A primeira oposição, perfectivo/imperfectivo, diz respeito à opção do falante por considerar o processo representado pelo predicado como um todo, considerando seu término, ou como uma subdivisão em fases, sem considerar o seu término, de modo que o processo seja considerado inconcluso. Os usos dos pretéritos perfeito e imperfeito são marcações gramaticais que ilustram essa opção aspectual. A diferença entre esses dois usos reside no aspecto e não na referência temporal ou cronológica, uma vez que os dois têm o passado como referência. A escolha entre, por exemplo, escrevi ou escrevia marca uma perspectiva em relação ao processo de escrever, estabelecendo, assim, determinada construção de sentido: um processo concluso (escrevi) ou uma fase de um processo que não se sabe se foi concluído ou não (escrevia), como podemos visualizar nos exemplos a seguir:

(1) a. Desde menor gosto de escrever, aos 14 anos escrevi um livro. ${ }^{\circ} 6$

b. Desde menor gosto de escrever, aos 14 anos escrevia um livro. *

Em (1b), marca-se uma fase do processo de escrever, sem precisar a conclusão ou não desse processo, diferentemente da opção (1a), na qual há a marcação do seu término.

A oposição perfectivo acabado por um lado e perfectivo indeterminado por outro é a principal subdivisão do aspecto perfectivo. De acordo com Ilari e Basso (2008, p. 290, grifos dos autores), "chamamos de acabado o perfectivo que mobiliza um MR [momento de referência]; o indeterminado é aquele em que a referência ao MR é dispensada". Trazemos, a seguir, os exemplos fornecidos pelos autores visando a ilustrar a diferença:

(2) a. Eu já morei aqui.

b. Eu já tinha morado aqui quando te conheci (ILARI e BASSO, 2008, p. 290).

Como podemos perceber, as duas sentenças representam processos conclusos (aspecto perfectivo), a diferença de aspecto estabelecida por elas reside na questão de que a troca entre as formas morei/tinha morado não pode ocorrer sem se considerar o momento de referência. Em (2a), o processo está concluso em relação ao momento da fala (MF) e não exige um MR, ao passo que em (2b), o processo revelado na expressão tinha morado está concluso em relação ao MF e também em relação a um MR (quando?) que essa opção aspectual passa a exigir. Dessa forma, (2a) é um exemplo de perfectivo indeterminado por dispensar um MR (quando?) e (2b) de perfectivo acabado por exigir um MR.

${ }^{6}$ Os exemplos marcados com ${ }^{\mathrm{o}}$ foram retirados do banco de dados do site: http://www. corpusdoportugues.org/. As frases marcadas com * são reconstruções para fins de explicação. 
A terceira oposição, progressivo/não progressivo, diz respeito às opções de descrição do processo em termos de duração do evento: com efeito de mostrar que há uma certa continuidade no processo, sem ser permanente, mas que exprime fatos dos quais se acompanha o desenvolvimento de forma simultânea ao momento de referência adotado (progressivo); ou com efeito de exprimir um evento que não possui esse caráter de desenvolvimento (não progressivo). Vejamos os exemplos a seguir:

(3) a. Ela está dormindo em minha casa, minha nova amiga de Alcoólicos Anônimos. ${ }^{\circ}$

b. Ela dorme em minha casa, minha nova amiga de Alcoólicos Anônimos.*

Em (3a), temos o aspecto progressivo, uma vez que o processo expresso indica um evento que se realiza simultaneamente ao momento da fala e esse momento representa uma fase de um processo com alguma extensão anterior e posterior a essa fase, mas não representa uma propriedade permanente. Em (3b) não temos esse caráter progressivo, pois exprime-se um evento pontual, habitual ou permanente, mas que não se realiza, necessariamente, no momento da fala.

Conforme Ilari e Basso (2008, p. 301, grifos dos autores), “a construção progressiva por excelência, em português, é estar + gerúndio". O uso dessa construção é bastante frequente no português brasileiro, principalmente, em conversas informais, e um dos fatores que contribuem para isso, segundo os autores, é que a perífrase "pode ser 'conjugada' praticamente em qualquer das formas de "estar"” (ILARI e BASSO, 2008, p. 301). Nesse sentido, podemos encontrar facilmente construções como:

\section{(4) Ela está / estava / esteve / tinha estado / estará / vai estar... dormindo.*}

Para Perini (2010, p. 233), as perífrases progressivas "expressam eventos em andamento, seja no presente, no passado ou no futuro. Algumas são mais correntes do que outras, mas não há levantamentos que permitam dar maiores detalhes a respeito".

Sob essa perspectiva, Bagno (2013, p. 289) alerta, contra aqueles discursos que condenam o uso frequente desse tipo de perífrase e denominam-no como gerundismo, sobre o fato de que não é o gerúndio que tem sido utilizado de forma problemática pelos falantes, "mas sim os verbos auxiliares que se acumulam diante do gerúndio". Assim, o que, na verdade, estaria causando estranheza aos ouvidos daqueles aos quais o autor chama de puristas é a utilização de diversos auxiliares nessas construções, como por exemplo: "vou poder estar assistindo TV" (BAGNO, 2013, p. 289). Conforme o autor:

Como se vê, o nome "gerundismo" não se aplica de modo algum ao fenômeno. A reação negativa de alguns falantes se deve principalmente ao emprego dessas perífrases onde a expressão do aspecto durativo própria do gerúndio parece inadequada quando se trata de ações pontuais ou ações perfectivas (com início e fim), que não implicam períodos de tempo indeterminados (...) (BAGNO, 2013, p. 290, grifos do autor).

Nesses termos, Bagno (2013, p. 290, grifos do autor), a partir de exemplos como "a Berenice já já vai estar atendendo a senhora" e "leve o guarda-chuva: quando você voltar pode estar chovendo", defende que é o aspecto que determina 
a adequação ou não da perífrase e não precisamente o uso do gerúndio. Para o autor, no primeiro exemplo, o processo encerra uma ação pontual e, por isso, o uso do gerúndio soaria inadequado, diferentemente do segundo exemplo em que o aspecto expresso é o imperfectivo e, portanto, não levantaria nenhuma reação negativa.

Longo e Campos (2002, p. 447), em análise da auxiliaridade em perífrases de tempo e de aspecto, trazem uma definição da aspectualidade como "categoria não dêitica através da qual se quantifica o evento expresso pelo verbo ou se expressa a constituição interna de fases, momentos ou intervalos de tempo que se incluem nesse evento". Conforme os autores, a expressão do aspecto verbal pode se dar a partir de várias formas na língua, como flexões, recursos derivacionais, construções de perífrases e elementos lexicais. Em português, por exemplo, podemos pensar que a escolha entre os elementos dormir e adormecer acontece de acordo com uma opção aspectual, isto é, de uma determinada perspectiva em relação ao evento expresso. Essa escolha baseia-se numa questão aspectual lexical e não gramatical, o que nos mostra a existência de dois domínios pelos quais o aspecto pode ser analisado, o domínio do aspecto lexical e o domínio do aspecto gramatical. ${ }^{7}$ Esse último, de acordo com Wachowicz e Foltran (2006), caracteriza-se, em geral, por uma morfologia flexional.

Tendo como base essas considerações relativamente à questão do aspecto no português brasileiro, a seguir, discutimos acerca dos usos das perífrases com gerúndio no diminutivo e as suas relações com as opções aspectuais.

\section{O DIMINUTIVO NA FORMA VERBAL DO GERÚNDIO NA FALA DO GUARAPUAVANO}

Se, conforme apresentado anteriormente, a perífrase estar + gerúndio é bastante produtiva e constitui a forma progressiva por excelência do português brasileiro, em Guarapuava, as construções com estar + gerúndio + inho parecem ainda mais produtivas. Isso é corroborado uma vez que o diminutivo -inho pode ocorrer, de acordo com as entrevistas realizadas para este estudo, em qualquer frase formada com gerúndio. ${ }^{8}$ Nesse sentido, podemos encontrar ocorrências como: ${ }^{9}$

\footnotetext{
${ }^{7}$ Para uma discussão mais aprofundada acerca das particularidades do aspecto lexical e do aspecto gramatical, recomendamos a leitura de Wachowicz e Foltran (2006).

${ }^{8}$ Uma pesquisa mais descritiva e quantitativa que busque investigar e formalizar em quais tipos de perífrase esse fenômeno acontece e até que ponto é o verbo auxiliar que determina a possibilidade de uso do diminutivo seria interessante e necessária para uma análise mais formal e detalhada sobre esses usos. Mas, dentro dos limites propostos neste trabalho, restringimo-nos, neste momento, a uma análise mais interpretativa do fenômeno, a partir dos dados obtidos em entrevistas informais e nossa experiência pessoal, buscando compreender a função das construções dessas perífrases.

${ }^{9}$ Essas ocorrências foram construídas para exemplificação, baseadas em exemplos citados pelos entrevistados, bem como em nossa experiência pessoal em relação aos usos desse tipo de construção na região de Guarapuava.
} 
(5) a. Ontem estava chovendinho aqui.

b. Eu estou passeandinho pelo centro da cidade.

c. Estou fazendinho o trabalho de português.

d. Eles estão namorandinho já faz tempo.

Partindo de nossa hipótese inicial de que usos como esses revelariam nuances aspectuais dos eventos expressos, realizamos entrevistas com dez pessoas que moram há pelo menos dez anos na cidade de Guarapuava-PR, para buscar informações a respeito da recorrência desses usos na fala cotidiana e a sua relação com o aspecto dos verbos. As entrevistas foram realizadas de forma informal e não tiveram como objetivo descrever as ocorrências do uso do diminutivo do gerúndio no momento das entrevistas, mas de procurar compreender se esses falantes consideram o seu uso com uma função específica em suas interações. Desse modo, os questionamentos que guiaram as entrevistas giraram em torno das seguintes questões: a) qual é a recorrência do uso (na fala do entrevistado e das pessoas com as quais convive) do diminutivo no gerúndio? b) a forma diminutiva substitui a forma do gerúndio sem o diminutivo em todos os contextos e/ou vice-versa? c) há diferença de sentido entre a forma diminutiva e a não diminutiva do gerúndio? Se sim, poderia citar alguns exemplos e as diferenças de sentido entre as formas?

A partir das respostas a esses questionamentos das entrevistas e de nossa experiência pessoal em relação às características da fala guarapuavana, chegamos a três características da utilização das perífrases com diminutivo do gerúndio que nos possibilitam defender a ideia de que se trata de uma questão relacionada a aspecto verbal, as quais esboçamos a seguir.

- Primeira característica: a coocorrência no sistema entre as formas primitivas e as formas diminutivas

A primeira característica diz respeito à coocorrência das perífrases construídas apenas no gerúndio (formas primitivas) com aquelas construídas no gerúndio diminutivo (formas diminutivas). Ou seja, as formas com o diminutivo não substituem as formas primitivas, mas coocorrem com elas dentro do sistema. Conforme as pessoas entrevistadas, pares como chovendo/chovendinho, passeando/passeandinho, namorando/namorandinho apresentam traços de significado distintos. Ambas as formas são utilizadas pelos falantes guarapuavanos, porém a escolha entre uma ou outra depende da situação, isto é, depende da nuance aspectual do evento pretendido pelo falante.

Assim, chovendinho significa uma chuva contínua, mas com menos intensidade e um ritmo mais lento em relação ao que exprime a forma chovendo. Passeandinho implica um processo contínuo, de ritmo lento, que estaria entre uma ideia de não estar fazendo nada e estar passeando. Estar namorandinho exprime um grau de compromisso menor entre os participantes em relação a estar namorando. Estar fazendinho um trabalho indica um processo mais lento do que o indicado por estar fazendo um trabalho (...). 
As discussões de Rocha (2016) acerca da não intercambialidade entre forma primitiva e forma diminutiva podem ser bem ilustradas com esses exemplos, ao passo que não se trata de uma escolha baseada em questões de ordem hipocorísticas, mas nos sentidos expressos pelos verbos com ou sem o diminutivo. As duas formas ocorrem no sistema, uma não substitui a outra. Desse modo, interpretamos que os sentidos provocados pelo diminutivo em formas gerundivas podem ser analisadas pelo seu estatuto aspectual.

Nesse sentido, o emprego do gerúndio no diminutivo evidencia o aspecto imperfectivo progressivo do processo expresso, ao mesmo tempo que imprime sentido abstrato diferente ao mesmo processo expresso apenas pela forma primitiva, relacionado à intensidade, ao ritmo ou à forma como o evento se realiza dentro de sua própria constituição interna. Temos aí um encaminhamento para a segunda característica.

- Segunda característica: a diferença semântica entre as formas diminutiva e primitiva reside numa dimensão aspectual do evento expresso

Retomando a conceituação da aspectualidade de Longo e Campos (2002, p. 447) como "categoria não dêitica através da qual se quantifica o evento expresso pelo verbo", podemos interpretar o uso ou não do morfema de diminutivo com o gerúndio como uma forma de quantificar a intensidade ou o ritmo desse evento. Vejamos mais alguns exemplos discutidos com os guarapuavanos entrevistados:

(6) a. Está esfriando hoje.

a’. Está esfriandinho hoje.

b. Fui correndo ao supermercado.

b'. Fui correndinho ao supermercado.

c. Ele está emagrecendo.

c'. Ele está emagrecendinho.

d. Ela já está melhorando.

d'. Ela já está melhorandinho.

Todas as ocorrências do diminutivo em (6) indicam que o processo expresso pelo verbo se dá em ritmo mais lento e menos intenso do que a forma primitiva do gerúndio. Em (6a') esfriandinho denota que o evento progressivo de esfriar se dá de forma mais lenta e menos intensa em relação a esfriando de (6a), isto é, não está tão frio como poderia estar. A corrida em processo em (6b') marcada pelo diminutivo é menos intensa, ou seja, mais lenta do que a corrida sem a marcação do diminutivo em (6b). O processo de emagrecimento em (6c') é mais lento e menos intenso na forma diminutiva. E em (6d'), a melhora expressa pelo diminutivo é também menos intensa e mais lenta quando comparada à forma melhorando de (6d). 
As relações entre os pares primitivo/diminutivo em (6) demonstram que a intensidade, o ritmo, a forma como o evento se desenvolve nesse período interno de tempo, é diferente entre as opções, em outras palavras, assumem perspectivas distintas.

De acordo com Basílio (1987), no que se refere aos motivos pelos quais os falantes formam palavras novas na língua, o uso de diminutivos é motivado por uma necessidade de acréscimo semântico à palavra. A autora estabelece dois fatos importantes em relação ao seu uso:

O primeiro é que o diminutivo é usado sobretudo para adicionar ao significado de uma palavra uma referência a uma dimensão pequena (sapato/sapatinho), para sinalizar uma linguagem afetiva (sopa/sopinha) ou para expressar pejoratividade (argumento/argumentozinho). O segundo é que o diminutivo sempre acompanha a classe da palavra básica à qual ele se aplica: livro/livrinho, baixo/baixinho - seja baixo adjetivo, como em homem baixo/baixinho, ou advérbio, como em falar baixo/baixinho (BASÍLIO, 1987, p. 09).

Nesses termos, o uso do diminutivo na forma gerundiva do verbo pode ser interpretado como uma necessidade de marcar uma outra dimensão, intensidade ou sentido do evento que não seria possível de outra forma ou a partir de outra classe gramatical. Assim, podemos pensar que a princípio há a criação de um neologismo para significar o aspecto verbal, pois busca-se incorporar outros sentidos abstratos ao evento expresso pelo verbo e à quantificação desse evento a partir de um morfema flexional disponível no sistema. Sinalizamos aqui a terceira característica.

- Terceira característica: as opções (primitivo vs. diminutivo) se exprimem por recursos gramaticais da lingua

Se, de acordo com Ilari e Basso (2008) e Longo e Campos (2002), as opções aspectuais se exprimem por meio de recursos como flexões e derivações os quais não se relacionam com referências temporais, mas com questões semânticas relacionadas à constituição interna dos eventos expressos, então os usos das perífrases em análise representam opções que caracterizam nuances aspectuais que se exprimem pela gramática da língua. Isto é, se exprimem pela presença ou não do morfema diminutivo com as formas gerundivas.

Conforme esboçamos na segunda seção deste trabalho, alguns autores, como Quadros (1966), Armelin (2011; 2015) Rocha (2016) e Guimarães e Mendes (2010), preveem formas gerundivas com o diminutivo, no entanto, não encontramos análises que descrevam especificamente as suas funções, apenas indícios de que podem se relacionar a grau em Rocha (2016), e em Guimarães e Mendes (2010) a especulação de que podem se tratar de questões aspectuais. Além disso, observamos que esses usos não são generalizados no português brasileiro, mas ocorrem em algumas regiões interioranas e, por isso, soam estranhas, como mais um tipo de gerundismo ou gíria, para pessoas advindas de outros lugares. 
Sob essa perspectiva, e corroborando a compreensão de que essas ocorrências fazem parte das regras gramaticais, recorremos ao que diz Basílio (1987, p. 26) sobre a questão da formação de palavras na língua:

como o léxico é um depósito de signos, uma lista de entradas lexicais, além de um conjunto de regras que definem a classe das palavras possíveis na língua, então é teoricamente possível (e ocorrente na prática) a situação em que encontramos na lista uma construção que não é prevista como possível no componente de regras.

Dessa forma, mesmo que o uso do diminutivo esteja mais frequentemente aliado às classes nominais, ele é possível e produz sentidos particulares nas formas verbais. Trata-se de recorrer a recursos presentes na gramática da língua (morfema de diminutivo) para a ampliação das possibilidades semânticas do verbo. Ter, portanto, a opção de marcar perspectivas distintas em relação ao ritmo e à intensidade dos eventos expressos pelo verbo usando ou não o diminutivo é, pois, contar com uma opção aspectual adicional.

Retomando a especulação de Guimarães e Mendes (2010) de que o uso do diminutivo em algumas variedades tenha produtividade diferente aliado a formas gerundivas e a participais por uma questão aspectual, reforçamos a alta produtividade do diminutivo no gerúndio na região de Guarapuava. Isso nos parece um forte indício de que o aspecto progressivo das formas gerundivas, por abrir um intervalo temporal, abre também uma forma de quantificar o ritmo, a dimensão, a intensidade do evento nesse mesmo intervalo.

Nesse sentido, as três características esboçadas nos possibilitam tratar os usos do gerúndio com ou sem morfema de diminutivo na região de Guarapuava como opções que carregam nuances aspectuais em relação ao processo expresso pelo verbo.

Nesses termos, a partir da classificação das opções aspectuais do português brasileiro de Ilari e Basso (2008, p.288) apresentada anteriormente, poderíamos sugerir a inclusão de uma subdivisão do aspecto progressivo, na variedade linguística da região de Guarapuava, que considerasse a oposição primitivo/diminutivo. Como discutimos, os usos das perífrases com gerúndio (primitivo) e com diminutivo do gerúndio (diminutivo) configuram duas perspectivas diferentes do mesmo processo desenvolvido progressivamente.

\section{CONCLUINDINHO}

Buscamos, neste trabalho, a partir da discussão acerca do aspecto do verbo no português brasileiro, refletir sobre os usos do diminutivo nas formas verbais em gerúndio na região de Guarapuava no Paraná, discutindo a hipótese de que esses usos refletiriam um modo de o falante contar com uma opção aspectual adicional em relação ao processo expresso pelo predicado. 
Por meio de uma análise interpretativa dos usos verificados a partir de nossa experiência pessoal, bem como, de entrevistas com pessoas que utilizam esse tipo de perífrase em suas falas cotidianas, pudemos esboçar três características dos usos do diminutivo no gerúndio que permitiram considerá-los como opções de nuances aspectuais. Assim, passamos a elencar tais características: a) a coocorrência no sistema entre as formas primitivas e as formas diminutivas; b) a diferença semântica entre as formas diminutiva e primitiva reside numa dimensão aspectual do evento expresso pelo verbo que não se resume em função hipocorística; e c) as opções (primitivo vs. diminutivo) se exprimem por recursos gramaticais da língua, isto é, pelo uso ou não do diminutivo.

Dessa forma, propomos que o uso do diminutivo em perífrases constituídas com gerúndio na variedade linguística da região de Guarapuava seja considerado como uma opção aspectual diferente em relação ao evento que se exprime sem o diminutivo. Ambas as formas são imperfectivas e progressivas, mas o processo progressivo em cada uma delas se exprime por um ritmo, uma dimensão ou intensidade distintas.

Utilizamos como subtítulos da seção introdutória e da seção conclusiva, respectivamente, introduzindinho e concluindinho visando a marcar que as discussões aqui realizadas não possuem um caráter de conclusão, mas de discussão inicial acerca dessas ocorrências dentro de uma variedade do português brasileiro. Nesse sentido, tanto introdutória como conclusivamente a dimensão deste trabalho recobre uma proposta de reflexão interpretativa com base em um contexto específico, mas que busca abrir um caminho possível no sentido de compreender a função desses usos num contexto mais amplo. Pesquisas exaustivas são necessárias para uma descrição mais formal do fenômeno.

\section{$\overline{\text { REFERÊNCIAS }}$}

ARMELIN, Paula Roberta Gabbai. Sobre a interação entre as marcas de diminutivo e aumentativo no português brasileiro. ReVEL, edição especial n. 5, 2011. Disponível em: <www.revel.inf.br>. Acesso em: 10 out. 2016.

ARMELIN, Paula Roberta Gabbai. A relação entre Gênero e Morfologia Avaliativa nos Nominais do Português Brasileiro: Uma Abordagem Sintática da Formação de Palavras. 2015. 247f. Tese (Doutorado em Linguística). Faculdade de Filosofia, Letras e Ciências Humanas. Universidade de São Paulo. São Paulo, 2015.

BAGNO, Marcos. Gramática de bolso do português brasileiro. São Paulo: Parábola Editorial, 2013.

BASÍLIO, Margarida. Teoria Lexical. São Paulo: Ática, 1987.

CARIELLO, Gabriel. Xé, correndinho, revertério! Gírias e sotaque do interior fazem parte de nossa identidade cultural. Disponível em: <http://interiometro.blogspot.com.br/2015/04/xecorrendinho-reverterio-girias-e.html>. Acesso em: 16 ago. 2016.

GUIMARÃES, Maximiliano; MENDES, Gesoel. Hipotetizandinho acerca do caráter infixal do morfema de diminutivo no PB. Handout apresentado no evento Tardes de Linguística na USP, realizado na Universidade de São Paulo, 2010. Disponível em: <http://linguistica.fflch.usp.br/ sites/linguistica.fflch.usp.br/files/Max-handout-27-05.pdf>. Acesso em: 11 set. 2017. 
ILARI, R.; BASSO, R.M. O verbo. In: ILARI, R.; NEVES, M.H.M. (Orgs.) Gramática do Português Culto Falado no Brasil. v. II. Classes de Palavras e Processos de Construção. Campinas: Ed. da Unicamp, 2008.

KENEDY, E; MARTELOTTA, M. E. T. A visão funcionalista da linguagem no século XX. In: CUNHA, Maria Angélica Furtado da; OLIVEIRA, Mariangela Rios; MARTELOTTA, Mário Eduardo Toscano (Orgs.). Linguística Funcional: teoria e prática. Rio de Janeiro: DP\&A / Faperj, 2003, pp. $17-28$.

LONGO, Beatriz de O.; CAMPOS, Odette de S. A auxiliaridade: perífrases de tempo e de aspecto no português falado. In.: ABAURRE, Maria Bernadete M.; RODRIGUES, Angela C. S. (Orgs.). Gramática do português falado. v. VIII. Novos Estudos descritivos. Campinas: Editora da Unicamp, 2002.

OLIVEIRA, Natália de. Comediante faz sucesso na internet com vídeos sobre gírias de Sorocaba. Disponível em: <http:/g1.globo.com/sao-paulo/sorocaba-jundiai/noticia/2016/01/comediante-fazsucesso-na-internet-com-videos-sobre-girias-de-sorocaba.html> Acesso em: 16 ago 2016.

PERINI, Mário A. Gramática do português brasileiro. São Paulo: Parábola Editorial, 2010.

QUADROS, Jânio. Curso prático da Lingua Portuguesa e sua literatura. v. II. Fonética e Fonologia. São Paulo: Editora Formar Limitada, 1966.

ROCHA, Rafael Martins. Diminutivos: uma análise morfossemântica de morfemas avaliativos do português brasileiro. 113f. Dissertação (Mestrado em Linguística) - PPGL, Universidade de Brasília, Brasília, 2016.

TEIXEIRA, Taize W. A forma e o uso dos sufixos -inho e -zinho em variedades do português do sul do Brasil. 2008. 95 f. Dissertação (Mestrado em Teoria e Análise Linguística). Universidade Federal do Rio Grande do Sul, Porto Alegre.

WACHOWICZ, Tereza Cristina; FOLTRAN, Maria José. Sobre a noção de aspecto. Caderno de Estudos Linguísticos. Campinas, v. 48, n. 2, pp. 211-232, 2006. 